\title{
Attitude and Practice of Treating Homosexual Community
}

Dr. AJ Manju

Head and Associate Professor

Department of English

Sree Narayana Guru College

Coimbatore, Tamil Nadu, India

manjumadhu57@gmail.com

Sreekesh K S

M.Phil Scholar

Sree Narayana Guru College.

Coimbatore, Tamil Nadu, India

sreekeshsnair96@gmail.com

\begin{abstract}
This paper gives a detailed summary about the perspective of the society about homosexuality also how society treats them. There we can go with the comparative study of old and new generation. By the behavior of the society, how the homosexuals feel about themselves and the homophobic people, how there bullying is effected by the homosexuals. Here I have taken a poem “Queer As In” by Riddhi Dastidar.
\end{abstract}

Keywords: Homosexuality, Society, Homophobia, Identity, Marriage

The word homosexuality is being considered in the different angles by different people. A word and the meaning and, thoughts which will be different from one person to another. 
Society itself will give different meaning and they will be having different perspective on a topic which will be end in big thoughts. Even now the term homosexuality is being considered as a sin. There are people who will not going to change and that represent the word 'sin'.

Culture places an important role here. We live in a society where people do follow the culture and there are some people which they are not following the same. When world changes the thought of a human being will also get changes and that represents it in the different areas of studies. In the generation basis, old generation which they lived their life in a different way so that they cannot digest such kind of concept, but still there is some exemptions. There are people who think it in a positive way. First and foremost, people should get into their mind that, homosexuality or any other changes based on queer, it is not a disease, rather it is something comes due to the hormone changes. Without looking in to the scientific way, there are so many people whom they interrupt in different aspects but it does not value at any point.

Self identity comes as a major factor because being a homosexual people gets fear of letting others to know about their identity. But, once identity is open to others, there comes a lot of questions also the high level of bullying from the society which will affect a person a lot. "Queer as in" by Riddhi Dastidar, in her poem she clearly portrays the emotions which queer people face in day to day life. As living in the society, they are not able to show their identity towards the society also they are limiting their emotion in themselves.

In her poem she clearly says that queer is something which should kept as secret. In real life we cannot show our identity because we are living in society. Always in a conscious mind about what people says once we let others know about their identity. It will affect the family the future generation. Always being in the conscious mind, there are so many people which they are not letting it to others. That is being a saddest part of the life. But, in the other hand, there are so 
many people who comes out with their identity and that replicates in the pride programs which gets conducted in world wide. Mass audiences which we can face over there in the pride. Gay, lesbians, bisexuals, transgender, transsexual, even heterosexual people were participating in the pride. This shows the success of the queer and slowly people has started to accept the same.

Today, there are so many queer based films, or short films which come out through social Medias. In all those movies, they have showed the happy aspects also the saddest aspect. But once we go in detailed life of a queer individual, in order to live their life as normal, what all difficulties which there facing in their life, which cannot be expressed. To live their life as normal, they are ready to do any kind of job. In the case of homosexuality there are gay marriages happening in our society also the concept of living together which is also happening in our society.

Queer people at some point they feel guilty, because people were looking at them as like they do a crime. As because of this, the political activism started to spread like something, which started in to some other issues. The issue about the society is like, people don't see them as a normal person at all. Being a gay, or lesbian, there character will not change but the affection, the love will gets change. In the $19^{\text {th }}$ and $20^{\text {th }}$ century, there are people who judged it as a mental illness, and regarding of it there are many theories which emerged after that.

By the beginning of the $21^{\text {st }}$ century, people has started to analyze it also started to discuss about the sexuality in a border way. As growing in the acceptance of homosexuality there are people who come out in much stronger way letting others to know about the identity and the sexuality? Today for homosexuals especially, there are so many dating applications which the homosexuals use it for sexual pleasure rather than being good friends. Once they had a sexual 
relation, it will haunt them without knowing them. And this makes a bad image for the other homosexual people.

Once an individual tell his identity to his family, automatically there will be much problems which will emerge there. Once you got married you will be alright. Such questions are being common with the people. Also people are having a misconception that through counciling people can change these issues. Without understanding the facts people will always give their ideas and points to make life beautiful.After one point, the homosexuals were started to hate the society because they are not getting the actual needs which they are suppose to get. Society is rejecting the love of such people and dominating them like something will make them sad. While others are enjoying their life and when heterosexuals were enjoying their life and when other people are enjoying their, homosexual community are not being happy. There were considered as taboo.

There is also people consider like, marriage is a social construct. Why marriage? For procreation and for pro construct the marriage is made. In order to make future generation, people are getting married and they are living with their own spouses. Actually marriage is not only constructed for procreation. It is like, when two parties are making a decision to live their life happily without actually causing problems. There are heterosexuals which they are married and living their life without having children. So we can't deny them for not living in this society.

Changes should happen in the society. The next step will be the adoption of a child. But according to the Indian penal code homosexuals don't have rights to adopt a child. The homophobic people always point out an issue based on it like what will be the mentality of the child once he or she grew up in the society. Society in general is not very accepting of LGBTIQ. There was lot of hatred towards them and prejudice mind against them. The reason behind this 
hatred and prejudice is ignorance. There are lot of misconceptions are preconceived notions about LGBT. People always think that being a gay or lesbian is a choice. But it is not a choice. If sexuality was a choice, they why straight people were decided to be heterosexual? So as like, heterosexuality is not choice as the same homosexuality is also not a choice either. Some people says that it is a western concept. There has been an increase in the number of teens coming out as LGBT as the norms around sexual and gender identity change. A relatively new phenomenon, the study of LGBT identified youth focuses on the risks and harms experienced by these vulnerable youth. However, most of the researchers focus on the experiences of LGBT identified people realizing that their identities have already been given. Therefore, this paper aims to understand how an individual becomes LGBT identifies and examines how sexual and gender identities are social and historical forms not biological facts. This work helps us to understand more about sociology of sexuality especially by exploring how teens perceive themselves as sexual and gender neutral.

Queer activism and theory have provided a counter to the urgent litigation in the LGBT rights movement and academia. Queer's theory questions the logic of an essential discourse and argues to break down binaries of sex and gender. Although they are still not widely accepted by the dominant society the ideas and challenges formed by the queer movement have begun to successfully thwart the normative ideas about sexuality and gender. These ideas shift the focus of social inequality from the focus of heteronormativity to how individuals become sexual and gendered. As a post modern theory queer theory rejects identities based on LGBT rights movements. The social constructivism and queer theory applied to the LGBT identities resulted in a kind of confusion. If sexuality is social and historical one, it is not biological but factual sexual orientation and identity that become slippery social positions for occupation and 
organization. A line between essential and constructive ideas about sexual desire is hellish and obscure.

"According to Conor Franta, You are still who you are, regardless of your gender, race, religion, or sexual orientation". A person has two slant in viewing a person who is involving with the society. An attitude on the other hand is relatively persistent organization of beliefs feelings and behavioral tendencies towards object, groups, or symbols of social significant. The society we live with a group of people with different understandings. Similarly, negative stereotype thoughts arise from the closeness of outside groups and social knowledge. In the case of heterosexual, homosexual dynamics, they may aso act as a security mechanism used to enforce group dominance and normalcy. This means that society still lacks ambiguity in its acceptance of homosexuality. The broader community of the LGBT community evokes the social attitudes of society towards them. The changes in society like their perspectives, ideas, norms, values, beliefs which brings a drastic change to the coming generation. At present it is quite tangible that there are so many changes that is happening in the society and society is trying to accept them. The study on LGBT focuses on determining an individual attitude towards the queer people by highlighting the idea that people in the LGBT community may have different attitude towards how they view, behave and communuicate.

As people are growing in the society, there perspective about the same will also get change. And that changes shows the acceptance of homosexual marriage which is currently happening in the society. The first gay couple of Kerala, they wish to adopt a child. There is nothing wrong in it. There are so many children whom they are living with the society without father and mother. While such things are happening in the society why a homosexual can couples can adopt a child. It means like, for a child they can give love and being a mother, they can give 
love and care those children. Here there will not be a role play of mother and father. Both of them will be the fathers of a child.

Why homophobic people are disagreeing with this homosexuality is just that the religious constitutions will get changes once the homosexual community get started to live their life. The religious constitution itself being in this society because of heterosexual construct. People can get more ideas or knowledge about homosexuality only through good education and also by reading. And such changes which we can see in the text books of school students. The main aim of gender studies in the universities is to know more about homosexuality towards the students and also to spread the knowledge to the students. Once the homosexual marriage is legalized, we can set some kind rules and regulation and the authority can encapsulate it. 


\section{Works Cited}

Dastidar Riddhi; Queer As In, The world that belongs to us, Aditi Angiras, Akhil Katyal, Thomson Press, 2020 Print 